\title{
The role of innate immunity in the long-term outcome of lung transplantation
}

\author{
Mitsuaki Kawashima, Stephen C. Juvet \\ Latner Thoracic Research Laboratories, University Health Network, University of Toronto, Toronto, Ontario, Canada \\ Contributions: (I) Conception and design: All authors; (II) Administrative support: SC Juvet; (III) Provision of study materials or patients: None; (IV) \\ Collection and assembly of data: M Kawashima; (V) Data analysis and interpretation: All authors; (VI) Manuscript writing: All authors; (VII) Final \\ approval of manuscript: All authors. \\ Correspondence to: Stephen C. Juvet. MD PhD FRCP(C). Assistant Professor of Medicine (Respirology), Toronto Lung Transplant Program, \\ University Health Network, University of Toronto, 2-401, 101 College Street, Toronto, ON, M5G 1L7, Canada. Email: Stephen.Juvet@uhn.ca.
}

\begin{abstract}
Long-term survival after lung transplantation remains suboptimal due to chronic lung allograft dysfunction (CLAD), a progressive scarring process affecting the graft. Although anti-donor alloimmunity is central to the pathogenesis of CLAD, its underlying mechanisms are not fully elucidated and it is neither preventable nor treatable using currently available immunosuppression. Recent evidence has shown that innate immune stimuli are fundamental to the development of CLAD. Here, we examine long-standing assumptions and new concepts linking innate immune activation to late lung allograft fibrosis.
\end{abstract}

Keywords: Immunity; innate; lung transplantation; graft rejection; fibrosis

Submitted Jan 10, 2020. Accepted for publication Feb 14, 2020.

doi: 10.21037/atm.2020.03.20

View this article at: http://dx.doi.org/10.21037/atm.2020.03.20

\section{Introduction}

Lung transplantation is a definitive option for patients with advanced respiratory failure. Nonetheless, its long-term survival is still limited to approximately $55 \%$ at five years, which is worse than following other types of solid organ transplantation (1). This poor outlook is mainly related to chronic lung allograft dysfunction (CLAD), an allograft scarring process driven by anti-donor alloimmune $T$ and $\mathrm{B}$ cell responses. Nevertheless, many aspects of CLAD pathogenesis remain obscure $(1,2)$. Since CLAD is neither preventable nor treatable using current immunosuppressive regimens, non-alloimmune processes are considered to be a key player in its development (3-5). Innate immunity encompasses a broad spectrum of immune responses mediated by elements of the immune system that are not reliant on antigen-specific somatically recombined receptors and classically do not have memory. Examples include responses mediated by polymorphonuclear leukocytes, macrophages, natural killer cells and parenchymal cells as well as the complement system. In this review, we will restrict ourselves to a discussion of innate stimuli relevant to lung transplantation and the pathways engaged by these stimuli, and we will conclude by examining postulated mechanisms linking innate immunity with lung allograft fibrosis.

Importantly, when bronchiolitis obliterans syndrome (BOS) is mentioned in older literature without reference to CLAD, it should be deemed to be synonymous with CLAD, since BOS was long regarded as its only manifestation. This state of affairs has changed since the recognition of restrictive allograft syndrome (RAS) in $2011(2,6)$.

\section{Molecular patterns associated with pathogens or injury}

A phylogenetically ancient set of receptors recognizes both pathogen-associated molecular patterns (PAMPs) and tissue damage-associated molecular patterns (DAMPs) and activates inflammatory responses. These patternrecognition receptors (PRRs), described below, are much older than the adaptive immune system that classically 
drives allograft rejection. They are essential for the host defense, but can have a detrimental effect on transplanted organs.

\section{Toll-like Receptors (TLRs)}

TLRs are highly conserved PRRs in mammals, and similar receptors are found in both vertebrates and invertebrates. They are genetically encoded and unlike $\mathrm{T}$ and $\mathrm{B}$ cell receptors, do not undergo somatic recombination, and are therefore identical on all cells in the host. Consequently, unlike specific antigen-reactive $\mathrm{T}$ and $\mathrm{B}$ cell receptors, they allow any cell expressing them to respond to their ligands. The widespread expression of TLRs therefore positions them in the first line of defense against pathogens (7). TLRs have leucine rich repeats (LRR) as a common structure (7). To date, 10 and 12 functional TLRs have been identified in humans and mice, respectively (8). TLRs are expressed on variety of immune cells and parenchymal cells, and their distribution is not equal across all cell types, which allows for functional specialization of cells equipped with specific TLRs. For instances, monocytes, macrophages and granulocytes express almost all the TLRs (9), positioning them to respond to a wide range of pathogens, whereas dendritic cells (DC) express different TLRs depending on their subtypes (e.g., myeloid DC vs. plasmacytoid DC) (10). Along with this, epithelial, endothelial, and mesenchymal cells express different TLRs (e.g., bronchial epithelial cells express TLRs 2, 3, 4 and 5) (9). These different expression patterns underlie distinct roles played by these cells in immune responses.

Each TLR recognizes specific PAMPs, which are typically microbial components, and provoke inflammatory cytokine secretion by responding cells. For instance, TLR2 and TLR4 recognize bacterial lipoproteins and lipopolysaccharide (LPS), respectively, and TLR3, 7, 9 recognize viral nucleic acids - double-stranded RNA, single-stranded RNA, and unmethylated $\mathrm{CpG}$ sequences (7). Each TLR has a prototypical ligand (e.g., LPS for TLR4), but can also recognize a wider array of bacterial, viral, fungal and endogenous DAMPs. As examples, TLR4 can recognize viral proteins of respiratory syncytial virus (RSV), cell wall mannans of Candida albicans, parasite proteins of Trypanosoma cruzi, and endogenous ligands (11-13). TLR2 and TLR4 are expressed on the cell membrane, whereas TLR 3, 7, 9 are positioned on endosomal membranes to recognize viral DNA or RNA found intracellularly. In addition to its surface expression, TLR4 is also found in the cytoplasm where it senses LPS escaped from phagolysosomes (7). Except for TLR3, TLRs signal via the adapter protein myeloid differentiation primary response gene 88 (MyD88) which triggers NF- $\mathrm{BB}$-dependent transcription in the nucleus leading to inflammatory cytokine release (7). Along with this, TLR3 and TLR4 signal via the toll-IL-1 receptor domain-containing adaptor inducing IFN- $\beta$ (TRIF) which causes type I interferon production (7). TLR4 uniquely has dual signaling pathways using either MyD88 or TRIF, whereas TLR3 only signals via TRIF. Activation of NF- $\mathrm{kB}$ and its target inflammatory genes by the various TLRs allows for a rapid response to PAMPs and DAMPs in the environment, before the adaptive immune system can be engaged. A more complete discussion of TLR pathways can be found in excellent recent reviews (7,11-13).

\section{DAMPs}

DAMPs are endogenous molecules released from injured cells, and modulate immune responses via cognate PRRs. DAMPs trigger what is known as "sterile" inflammation, since it can occur in the absence of pathogens (14). Dying cells release many DAMPs, and also "stressed" but still living cells can expose DAMPs on their plasma membranes. Examples of DAMPs are high mobility group box 1 (HMGB1), heat-shock protein (HSP) 72, hyaluronan (HA), heparan sulfate, S100 proteins (S100 A1/8/9/12), extracellular adenosine triphosphate (eATP), and mitochondrial DNA (mtDNA) (15). Some DAMPs like HMGB1 and HSP 72 are derived from intracellular compartments, whereas other DAMPs such as HA and heparan sulfate are generated from damaged extracellular matrix (15). HMGB1 is one of the best-studied DAMPs. It is a nucleic acid binding protein and released from dying cells when they lose cell membrane integrity. HMGB-1 is recognized by TLR2/4 and receptor for advanced glycation end product (RAGE), and provoke inflammatory reactions (15).

RAGE is multiligand receptor recognizing DAMPs like HMGB1 and S100 proteins, and was originally discovered to engage advanced glycation end products $(16,17)$. RAGE is a transmembrane receptor expressed on all cells but is abundant in pulmonary endothelial and type I alveolar epithelial cells $(16,18)$. RAGE ligation results in intracellular signal transduction through activation of NF- $\mathrm{\kappa B}(16,18,19)$. A unique function of RAGE is de novo synthesis of NF$\kappa B p 65$ resulting in the accumulation of $\mathrm{NF}-\kappa \mathrm{B}$ in the 
cell $(16,18)$. Thus, this system can perpetuate sustained inflammation, and is believed to have a role in development of chronic inflammatory diseases $(16,18)$. Owing to the enrichment of RAGE in the lung, RAGE contributes to pulmonary inflammation and mechanisms of lung diseases like emphysema and pulmonary fibrosis (20-22).

Soluble RAGE (sRAGE) is generated as a result of cleavage of the transmembrane form of RAGE or via active secretion. sRAGE does not transduce signals, and instead functions as a decoy receptor which prevents RAGE from engaging with its ligand (16,23). Recently, sRAGE has been recognized as a marker of type I alveolar epithelial cell injury and can be found in bronchoalveolar lavage (BAL) and plasma as a result of acute lung injury $(24,25)$.

\section{Inflammasomes}

Inflammasomes are large cytoplasmic protein complexes activated via TLRs and another type of PRR: nucleotidebinding oligomerization domain-containing protein (NOD)-like receptors (NLRs) $(5,14)$. A representative and well-studied example is the NLRP3 (NOD-, LRR- and pyrin domain-containing protein 3) inflammasome (5). NLRP3 inflammasome is activated in two stages: signal 1 (priming) and 2 (activation). In signal 1, PAMPs/DAMPs and other stimuli (TNF-alpha, IL-1beta, IFN) bind to their cell surface receptors and activate NF- $\mathrm{\kappa B}$-dependent transcription of NLRP3, pro-IL1b and pro-IL-18 (2628). In signal 2, PAMPs/DAMPs and complement components damage mitochondria and lysosomes resulting in accumulation of reactive oxygen species (ROS) and cathepsin $\mathrm{B}$ as well as causing $\mathrm{K}^{+}$efflux and $\mathrm{Ca}^{2+}$ influx. All of these are stimuli for NLRP3 inflammasome assembly (26-28). The assembled NLRP3 inflammasome is a large multimeric complex that includes NLRP3, ASC, and procaspase 1 . Then, activated caspase 1 cleaves pro-IL-1b/-18 to produce IL-1b/-18, which propagate inflammation. There are also non-canonical NLRP3 inflammasome activation systems which are triggered by cytosolic sensing of LPS not by surface-membrane TLR4 engagement (2628). The NLRP3 inflammasome also mediates induction of gasdermin D-dependent pyroptotic cell death, an inflammatory mode of regulated-cell death $(27,28)$.

\section{Regulated cell death}

Stressed or injured cells release their intracellular contents as DAMPs, but the extent of release differs depending on the type of cell death (29). Accidental cell death occurs as a result of mechanical or chemical stress with rupture of the cell membrane and the release of highly immunogenic cell contents. Importantly, some injured cells can retain their cellular integrity, but others may undergo one or more modes of regulated cell death (RCD) where the degree of resulting inflammatory signaling differs depending on the type of RCD $(29,30)$. Pyroptosis, ferroptosis, and necroptosis are generally pro-inflammatory, immunogenic types of RCD since they cause eventual cell membrane rupture with release of cytosolic DAMPs into the extracellular space where they can provoke inflammation; in contrast, apoptosis is the least immunogenic form of RCD as cell membranes remain intact until apoptotic bodies are phagocytosed (30).

Clearance of dying and dead cells are pivotal mechanisms to alleviate sterile inflammatory responses. Efferocytosis is the clearance of apoptotic cells, which typically express surface markers that act as "eat-me" signals such as phosphatidylserine $(31,32)$. In contrast, complement components and mannose-binding lectin attach to apoptotic and necroptotic cells and promote opsonization and efferocytosis (33). When these cell clearance systems fail, dying cells persist and cause delayed elimination of autoantigens, a process that has been linked to the development of some of autoimmune diseases like systemic lupus erythematosus and autoimmune lymphoproliferative syndrome (34). In this vein, it is worth noting that autoantigen-directed immune responses can contribute to CLAD pathogenesis $(35,36)$.

\section{Innate immunity is an important contributor to the development of CLAD}

The role of TLR signaling in lung transplantation has been explored in both human and animal studies. TLR4 is one of the best characterized innate immune receptors. In a seminal observation, Palmer and colleagues reported that lung transplant recipients who had polymorphisms in the TLR4 gene that conferred decreased TLR4 function showed a lower incidence of acute rejection, but donor TLR4 polymorphism did not affect outcomes (37). Hypo-functional recipient TLR4 polymorphism was also associated with a lower incidence of the composite outcome of CLAD and death, with no differences in the rate of bacterial infections (38). In another report, a recipient polymorphism (rs2569190) of CD14, an LPS co-receptor that promotes TLR4 signaling, was associated with a higher 
incidence of CLAD (39). Since this polymorphism increases transcriptional activity of CD14 compared to heterozygotes or wild-type, patients with this polymorphism have elevated innate immune activation, which might have contributed to CLAD development. Given these two opposing phenotypes arising from different TLR4 and CD14 polymorphisms, the authors concluded that TLR4 signaling contributes to allograft rejection (37-39). Interestingly, Kastelijn and associates examined polymorphisms of TLR1 to TLR10 in lung transplant recipients and found that specific polymorphisms of $T L R 2,4$, or 9 were associated with a higher incidence of CLAD (40). Importantly, the TLR4 polymorphism (rs1927911) they found to be associated with CLAD was different from the ones that Palmer and associates examined [rs4986790 (Asp299Gly), rs4986791 (Thr399Ile)] $(37,38,40,41)$. These data suggest that TLR signaling modulates CLAD development, but the specific roles of individual TLRs depend on population genetic variation and context (donor $v s$. recipient). How polymorphisms across different TLRs interact to influence CLAD risk is unknown and requires further study.

There is also some evidence that specific DAMPs have an important role in CLAD pathogenesis. Tesar and associates reported that higher HA concentrations in the BAL of lung transplant recipients was associated with CLAD (42). Further, Todd and colleagues showed that HA is localized within areas of small airway fibrosis in CLAD lung tissue, and both BAL and plasma HA concentrations were elevated in CLAD patients compared with CLADfree patients (43). The Toronto group has also reported a distinct expression pattern of DAMPs (HMGB1 and S100 proteins) in BAL obtained after a diagnosis of BOS or RAS (44). These reports suggest that DAMPs accumulate in lung allografts affected by CLAD and may be involved in CLAD development.

Using a mouse skin transplant model, Tesar and colleagues showed that HA accumulated in rejected grafts, and that HA can stimulate DCs to produce cytokines and chemokines mainly through TLR4 and partly through TLR2 signaling (42). In a mouse orthotopic lung transplantation model, Todd and associates showed that administration of low-molecular-weight HA prevented tolerance induction through TLR2/4- and MyD88signaling, whereas high-molecular-weight HA ameliorated allograft inflammation (43). These findings support the clinical observation that DAMPs accumulate inside the allograft, and are associated with graft outcomes.

Shah and associates reported that plasma sRAGE concentrations within 24 hours after lung transplantation were an independent risk factor of CLAD, even after adjustment for PGD (45). This finding suggests plasma sRAGE is a more sensitive marker of relevant allograft damage than PGD itself, from the perspective of future CLAD risk. Importantly, however, sRAGE did not show clear differences in BAL obtained after a diagnosis of BOS or RAS (44). Taken together, these studies suggest that early, rather than late, sRAGE levels may be a useful predictor of CLAD and that sRAGE is a potentially useful biomarker of lung allograft injury.

\section{Sterile inflammation at the time of transplantation can influence short- and long- term outcomes}

\section{Potential role of innate immunity before transplantation}

Donor organs are exposed to innate immune stimuli even before transplantation, which may have a role in subsequent IRI and graft outcomes. For instance, brain death is known to have a harmful effect on donor lung through neurogenic pulmonary edema, pro-inflammatory cytokine release, and an influx of inflammatory cells (46-49). In addition to these phenomena, innate immunity may link donor brain death to the degree of subsequent IRI. Rostron and colleagues observed that TLR2/4 signaling mediated lung injury following donor brain death in a rat model (50). Wang and associates showed that donor brain death combined with hemorrhagic shock and prolonged cold ischemia can stimulate necroptosis in the graft (51). Further, Zweers and colleagues found that donor brain death aggravated chronic rejection in a rat lung transplantation (46). In a liver transplantation model, brain death stimulated S100 protein accumulation in the graft (52). These findings indicate that innate immunity has a role even before transplantation, and that this process likely contributes to lung allograft injury at the time of transplantation.

\section{Primary graft dysfunction: a brief overview}

Given the nature of the organ procurement and storage process, ischemia reperfusion injury (IRI) is inevitable in solid organ transplantation, and innate immunity plays a key role in its pathogenesis. Ischemia, defined as a lack of blood perfusion, causes hypoxic stress, which arises from an imbalance between tissue demand and capillary supply of oxygen and nutrition. Cold preservation of grafts after 
procurement serves to lower the metabolic rate of allograft parenchymal cells and hence can reduce the degree of IRI. Reperfusion injury occurs following the resumption of blood flow to the ischemic graft following vascular anastomosis, and is mediated by reactive oxygen species, which damage allograft parenchymal cells. DAMPs are released by stressed or damaged cells, activate TLRs, RAGE, and inflammasomes, and then trigger inflammatory cytokine secretion aggravating IRI and leading to PGD in severe cases.

\section{Animal data demonstrating the role of innate immunity in IRI}

A substantial body of research supports the role of innate immunity in pathogenesis of IRI. Shimamoto et al. reported that TLR4 knockout mice had a reduction in vascular permeability and leukocyte inflammation compared with TLR4-sufficient mice in a hilar clamp model of warm IRI (53). Ishiyama and associates showed that NF- $\kappa \mathrm{B}$ inhibition ameliorated IRI in a rat lung transplantation model (54). Interestingly, Zanotti and colleagues reported that TLR4 signaling by stromal, rather than hematopoietic cells, is responsible for lung edema caused by IRI (55). Merry et al. inhibited TLR4 signaling using small interfering RNA (siRNA) in a rat hilar clamp model, thus efficiently inhibiting downstream c-Jun $\mathrm{N}$-terminal kinase signaling, and decreasing vascular permeability and inflammation (56). Also, in a hilar clamp model, Takahashi and associates showed that acute hyperglycemia exacerbated IRI through up-regulation of TLR4 signaling (57). Collectively, these findings suggest recipient TLR signaling is actively involved in the pathogenesis of lung IRI, which implicates DAMPs released from damaged/stressed cells in the process.

Given that DAMPs can be released as a result of immunogenic cell death, control of RCD pathways may mitigate the severity of IRI. For example, Del Sorbo and colleagues suppressed apoptosis using siRNA targeting the pro-apoptotic molecule Fas, improving lung function in a mouse IRI model (58). Xu et al. showed that RIPK3and MLKL-dependent necroptosis was upregulated in rat lungs undergoing IRI (59). Mingyao Liu's group showed that IRI induces necroptosis in human lung epithelial cells, and that this process could be prevented by necrostatin (inhibitor of RIPK3 mediated phosphorylation) in vitro (60); in a subsequent study, the same group showed that IRI could be prevented by administration of necrostatin in a rat orthotopic lung transplant model (61). Noda et al. found that circulating leukocytes in a rat ex vivo lung perfusion (EVLP) model underwent pyroptotic cell death, and removing those cells improved graft function (62). Although these authors did not examine levels of DAMPs released during the various modes of cell death examined, the data suggest that targeting RCD may provide a benefit in lung transplantation, presumably through a reduction in DAMPs release.

Mitochondrial DAMPs (mtDAMPs) are another key innate immune molecule that help to drive IRI. Damaged mitochondria release mtDAMPs such as mtDNA and $\mathrm{N}$-formylated peptides which can activate TLR9 and formylated peptide receptor 1 (FPR1), respectively. Mallavia and associates reported that mtDNA activates TLR9 and triggers neutrophil extracellular trap formation in mouse lung grafts that underwent prolonged preservation and transplantation, driving IRI (63). Scozzi and colleagues showed that FPR1 is important for neutrophil trafficking, ROS production, and graft edema in a mouse lung transplant model, further demonstrating that mtDAMPs contribute to the pathogenesis of IRI (64).

Some studies have suggested an association between RAGE and allograft injury and fibrosis. Sternberg and associates' mouse hilar clamp model showed that RAGE signaling is involved in IRI and that RAGE blockade with exogenous sRAGE improved lung function (65). He and colleagues reported that HMGB1 exacerbated fibrotic obliteration airway lesions through RAGE and NF- $\mathrm{KB}$ in a mouse tracheal transplantation model (66). Intriguingly, Sharma and colleagues reported that RAGE expressed on invariant natural killer T (iNKT) cells mediates IRI in a mouse model, which resulted in iNKT cell IL-17 production (67). These reports suggest RAGE signaling may have a role in lung allograft rejection.

\section{Clinical evidence of relationships between innate immunity and PGD}

Andrade and associates measured TLR mRNA level in human lung allografts before and after reperfusion and reported that TLR mRNA levels at the end of cold ischemic time (CIT) were correlated with cytokine expression. They also showed that (I) TLR2 mRNA at the end of CIT was correlated with donor intubation time; (II) TLR4 mRNA level after reperfusion was correlated with recipient age; (III) HSP70 mRNA increased with time after reperfusion (68). Cantu and colleagues found that genes encoding NLR inflammasomes, TLR4, TLR9, and 
MyD88 were upregulated in the BAL of PGD patients (69). In a subsequent study, they found that genetic variation in Toll interacting protein (TOLLIP), which regulates TLR signaling, was associated with the risk of PGD (70). Xu and colleagues found that TLR pathway components (e.g., TLR4, IRAK1/3, MyD88, etc.) were overexpressed in the BAL of recipients who developed PGD (71). Shafaghi and associates reported that EVLP may alter TLR expression in the donor lung (72). In terms of mtDNA, Scozzi and associates showed high level of plasma mtDNA was associated with the development of severe PGD (64). Supporting the concept that sRAGE may be a useful biomarker, Calfee and colleagues reported that plasma sRAGE level was related to duration of intensive care unit stay and mechanical ventilation (25). In a subsequent multicenter study, Christie and colleagues also showed that elevated plasma sRAGE within 24 hrs of reperfusion was associated with PGD, blood transfusion and the use of cardiopulmonary bypass (18). Pelaez et al. showed that sRAGE in donor BAL is a risk factor of PGD (73). Taken together, these findings suggest that innate immune responses involving TLRs, RAGE, and inflammasomes have a key role in pathogenesis of human PGD, which are in line with the animal data.

\section{$P G D$ is a risk factor of CLAD}

So far, we have summarized the role of innate immunity in PGD, which is an early complication of lung transplantation. But PGD is itself associated with worse long-term outcomes (74-80), for reasons that remain incompletely understood. The consensus suggests that cell death and tissue damage caused by IRI augments alloimmune responses through upregulation of MHC and costimulatory molecules, exacerbating acute cellular rejection and humoral rejection (81-84). It seems unlikely that this is the only pathway linking IRI and CLAD, since conventional immunosuppression, which should control alloimmunity, fails to prevent CLAD. In this regard, it is noteworthy that IRI also causes the release of pro-fibrotic cytokines such as TGF-beta, which could help to promote CLAD via a pathway independent of the adaptive immune system (80). Mediator release from injured stromal cells may also drive a pathway linking IRI to CLAD by recruiting and spatially organizing a unique intragraft immune response. In support of this concept, we recently observed that IRI alters chemokine release from the graft and stimulates tertiary lymphoid organ formation within the lung in a mouse orthotopic lung transplant model (85), suggesting that IRI may modify the quality of the downstream alloimmune response and not just its magnitude.

\section{Noxious post-transplant stimuli also drive CLAD via innate immunity}

The lung is constantly exposed to the external environment via the airways, whereas heart, liver and kidney allografts are protected inside the body. This characteristic may account for the fact that lung transplantation has a worse outcome than other forms of solid organ transplantation. Pulmonary infection, gastro-esophageal reflux disease (GERD), smoking and even air pollutants (e.g., particulates, NOx), irritate airway epithelial cells and cause inflammation, which can enhance the risk of CLAD (4).

The lung harbours an endogenous microbiome whose diversity has been shown to be altered post-transplant (86). Outgrowth of pathogenic bacteria within the lung either as an acute or chronic infection trigger inflammation via TLRs and can augment alloimmune responses via a variety of mechanisms-including bystander activation, heterologous immunity, and enhanced alloantigen presentation (87). It is well established that Pseudomonas aeruginosa colonization and infection are risk factors of CLAD (88-92). Pulmonary infection by RSV $(93,94)$, cytomegalovirus (CMV) (95-97), and Aspergillus $(98,99)$ are known risk factors for CLAD development. There is even a report that regardless of the specific organism isolated, pulmonary infection is associated with CLAD (100). These findings are supported by abundant animal data using various rodent lung, tracheal, and bone marrow transplant models (101-108). Caution is warranted, however: there is also evidence that acquisition of a benign microbiome, or colonization without inflammation, does not have a harmful impact. Law and colleagues showed that Aspergillus colonization was not associated with CLAD risk in a multicenter study (109). Pritchard and associates showed that Pseudomonas aeruginosa infection is not a risk factor for CLAD in cystic fibrosis (CF) patients (110). Schott et al. reported that colonization by gram-positive bacteria is protective from CLAD (111), and Willner et al. reported that in CF lung transplant recipients, re-acquisition of Pseudomonas strains that had been present before transplant reduced the risk of CLAD; in contrast, de novo acquisition of microbial populations increased CLAD risk (112). Taken together, pulmonary microbial infections are generally believed to have detrimental effects on graft function, but those effects are likely to vary on the 
basis of incompletely understood recipient factors. This is an area that would benefit from additional mechanistic and prospective clinical studies.

Since the esophagus and the trachea are anatomically connected at the larynx, the lung is at risk of exposure to gastric contents via GERD. GERD is a risk factor of CLAD, and some data support the use of surgical fundoplication to prevent lung function decline in lung transplant recipients with GERD (113-115). There are rat studies showing that gastric acid aspiration can cause fibrosis in lung allograft (116-118) but interestingly, weakly acid ( $\mathrm{pH} 4-7)$ and non-acid reflux are also risk factors for CLAD (119-121). This observation suggests that acidity is not the primary factor mediating CLAD in lung transplant recipients with GERD. Other components of gastric juice such as bile acids (122-124) and bacteria which may activate PRRs, may drive CLAD development in patients with GERD. Presumably, the complex chemical and microbiological constituents of gastric juice-including a variety of PAMPs and DAMPscollectively cause airway epithelial cell injury and death, leading to further DAMPs release and activation of innate and adaptive immunity. Further research is needed to understand how GERD initiates these injurious pathways.

Air pollution is another important contributor to the development of CLAD. In different geographic areas, Nawrot et al. (125) and Bhinder and colleagues (126) reported that exposure to traffic-related air pollution was associated with CLAD development and death. Verleden and associates reported that, in patients not taking azithromycin, the atmospheric level of particulate matter of 10 microns in size or smaller $\left(\mathrm{PM}_{10}\right)$ was associated with lymphocytic bronchiolitis (LB), a well-known risk factor for CLAD (127). Similarly, Ruttens et al. reported that $\mathrm{PM}_{10}$ and traffic exposure were associated with CLAD and survival in patients not taking macrolides (128). Benmerad et al. reported levels of air pollutants $\left(\mathrm{PM}_{10}, \mathrm{PM}_{2.5}, \mathrm{NO}_{2}\right)$ were associated with lower forced expiratory volume in one second (FEV1) and forced vital capacity in \% predicted in lung transplant recipients, and that the effect was stronger in patients not taking macrolides (129). The mechanisms by which air pollution predisposes lung transplant recipients to CLAD is not entirely clear, but hypothetically airborne small particles and hyperoxidants irritate the epithelial cells of small bronchi then cause airway-centered local inflammation and bronchial fibrosis. This is another area that is ripe for mechanistic study.

\section{How innate immunity causes fibrosis in the lung allograft}

The data we have reviewed here suggests that there are, at a minimum, three mechanisms by which innate immunity may drive CLAD (87). Firstly, recognition of PAMPs/DAMPs by PRRs stimulate dendritic cellsand other antigen-presenting cells-to mature via NF$\kappa \mathrm{B}$ transcription. Secondly, immune cells recognizing PAMPs/DAMPs release pro-inflammatory cytokines which promote differentiation of alloreactive $T$ cells via bystander activation. Thirdly, immune cells sensitized with microbial antigens can have cross-reactivity to the alloantigen-MHC complex-a process known as heterologous immunity. These augmented alloimmune responses cause allograft damage, which can if self-limited be repaired by fibroblasts, myofibroblasts and epithelial regeneration. Fibroblasts can be activated by TGF- $\beta 1$, and secrete collagen to repair and reconstruct injured tissues. This process normally terminates when tissue repair is completed, but may persist in the case of sustained innate immune activation, leading to excess repair and fibrotic tissue remodeling, which finally cause organ fibrosis (130).

Although existing data support this model, our view is that allograft inflammation alters the quality of the antidonor response, and not just its magnitude. Observations that monocytes can respond to allogeneic determinants $(131,132)$ and that T cells can contribute to IRI $(133,134)$ illustrate that distinctions between conventionally "innate" and "adaptive" arms of the immune system may not be as clear as once thought. Further, recent data from our group demonstrate a critical role for recipient B cells in the development of CLAD-like fibrosis after IRI in a mouse model (85), a process that also involved the formation of intragraft tertiary lymphoid organs. Here, B cells might contribute to the link between IRI and fibrosis simply through enhanced alloantigen presentation to $\mathrm{T}$ cells - but there may also be unanticipated specific B cell pathways engaged via IRI that are yet to be determined. Our recent finding that the appearance of specific $\mathrm{T}$ cell phenotypes in the BAL anticipates subsequent loss of lung function $(135,136)$ also illustrates that the nature of the immune response may be altered in grafts destined to undergo fibrosis.

Another likely mechanism linking allograft inflammation to fibrosis bypasses the conventional adaptive immune response. Borthwick and associates showed that Pseudomonas can cause lung epithelial cells to release IL-1alpha via TLR 
signaling, a process that activated lung fibroblasts to secrete IL-6 and -8 in vitro (137). Additionally, LPS can interact with TGF- $\beta 1$ to activate fibroblasts independently from $\mathrm{T}$ cell interaction $(138,139)$.

Taken together, the data suggest that controlling both inflammation and alloimmunity is likely to be crucial to prevent sustained fibroblast activation, matrix remodeling and tissue fibrosis.

\section{Innate immunity to differentiate CLAD into phenotypes of BOS and RAS?}

Historically, chronic lung allograft rejection was believed to be a uniform process of obliterative bronchiolitis and, since definitive lung biopsies often cannot be obtained, was termed BOS based on the occurrence of nonreversible airflow limitation on pulmonary function testing. Subsequently, Sato et al. recognized that a restrictive phenotype of chronic rejection exists and called it RAS, which is less common than BOS but has a poorer survival (6). Other variants of CLAD (e.g., mixed, undefined, etc.) have been defined in recent guidelines (2). Whether there are distinct immunological mechanisms leading to BOS and RAS is unknown, but we predict that the nature, location and extent of innate immune activation in the lung allograft may be a key determinant.

IRI is a widespread injury leading to diffuse alveolar damage (DAD), manifesting clinically as PGD. The areas affected may be more susceptible to later fibrosis, leading to RAS-type CLAD. Our mouse data revealed that IRI leads to RAS-like pathology at day 28 accompanied by tertiary lymphoid organs containing $\mathrm{T}$ and $\mathrm{B}$ cells (85). These findings are similar to human RAS pathology (140). In humans, however, IRI and PGD may not be a specific risk factor of RAS since Sato and associates reported that late $\mathrm{DAD}$ was a risk factor for RAS, but early DAD was a risk factor for BOS (141). Nevertheless, the concept that RAS results from a more severe and widespread injury than does BOS is in keeping with the recent observation that cytokeratin 18 fragments - biomarkers of epithelial cell death-are much more greatly elevated in the BAL of RAS patients than in the BAL of BOS patients (142). The mechanisms by which IRI and PGD drive CLAD requires further clarification.

Noxious stimuli arriving in the graft via the airways might reasonably be expected to drive BOS-type CLAD development since the airways are the site of inflammation in this context. Indeed, most animal lung transplant models of CLAD that include deliberate airway inflammation demonstrate obliterative bronchiolitis $(117,118,143,144)$. We speculate, however, that the effects of external stimuli may be non-uniform and variable depending on whether they cause localized epithelial or a deeper diffuse alveolar injury. For instance, in the case of localized epithelial infection (e.g., bronchitis), inflammation may be limited to the airways leaving the parenchyma unaffected, which may lead to airway-centered fibrosis. In the case of a more diffuse alveolitis acquired via the airways (e.g., lobar pneumonia, severe influenza), infection may have a much broader effect on the allograft, which could drive diffuse fibrosis leading to RAS.

These hypotheses should be examined in greater detail using more complex animal models and human biospecimens. Undoubtedly, CLAD pathogenesis in human lung transplant recipients is far more complex than in the experimental settings described, but in our view, there remains a lot to be learned from careful animal experiments designed to test relationships between inflammatory injury and allograft fibrosis.

\section{Conclusions}

Innate immunity promotes inflammation, alloimmunity, and fibrotic processes in the lung allograft, which are important for development of CLAD (Figure 1). After reperfusion, innate immune responses trigger IRI and PGD, which is a risk-factor for later CLAD onset. Subsequent innate immune stimuli from the external environment provoke further inflammation and complex interactions between immune cells in the graft. It is very likely that the conventional adaptive immune response is profoundly altered in both magnitude and quality by allograft inflammation. Since CLAD is not preventable using current immunosuppression, dissecting the innate immune contribution to the pathogenesis of CLAD is a critical focus for research in lung transplantation. 


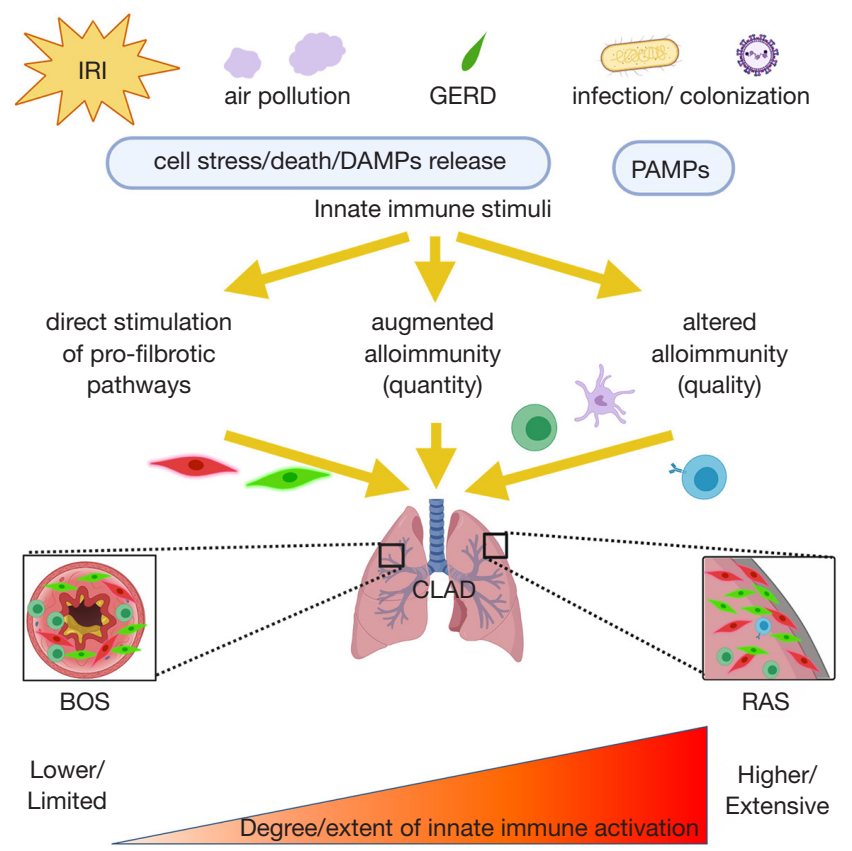

Figure 1 Proposed innate immune mechanisms leading to CLAD. Innate immune stimuli may drive pro-fibrotic pathways directly, enhance the magnitude of the alloimmune response or alter its quality, leading to CLAD. We propose that more limited activation of the innate immune system in the small airways underlies BOS, while RAS arises from more severe and widespread inflammation. IRI, ischemiareperfusion injury; GERD, gastro-esophageal reflux disease; DAMPs, damage-associated molecular patterns; PAMPs, pathogen-associated molecular patterns; CLAD, chronic lung allograft dysfunction; BOS, bronchiolitis obliterans syndrome; RAS, restrictive allograft syndrome.

\section{Acknowledgments}

We would like to thank Drs. Tatsuaki Watanabe and Tereza Martinu for meaningful discussions.

Funding: None

\section{Footnote}

Provenance and Peer Review: This article was commissioned by the Guest Editors (Masaaki Sato and Dong Tian) for the series "Strategies to Achieve Long-Term Success of Lung Transplantation" published in Annals of Translational Medicine. The article was sent for external peer review organized by the Guest Editors and the editorial office.

Conflicts of Interest: The series "Strategies to Achieve LongTerm Success of Lung Transplantation" was commissioned by the editorial office without any funding or sponsorship. SJ has grant support from the Ontario Thoracic Society Grant-in-Aid, the Caron Thorburn Foundation and from the US Cystic Fibrosis Foundation. SJ has received research grant support from Sanofi. The other authors have no other conflicts of interest to declare.

Ethical Statement: The authors are accountable for all aspects of the work in ensuring that questions related to the accuracy or integrity of any part of the work are appropriately investigated and resolved.

Open Access Statement: This is an Open Access article distributed in accordance with the Creative Commons Attribution-NonCommercial-NoDerivs 4.0 International License (CC BY-NC-ND 4.0), which permits the noncommercial replication and distribution of the article with the strict proviso that no changes or edits are made and the original work is properly cited (including links to both the formal publication through the relevant DOI and the license). See: https://creativecommons.org/licenses/by-nc-nd/4.0/.

\section{References}

1. Chambers DC, Cherikh WS, Harhay MO, et al. The 
International Thoracic Organ Transplant Registry of the International Society for Heart and Lung Transplantation: Thirty-sixth adult lung and heart-lung transplantation Report-2019; Focus theme: Donor and recipient size match. J Heart Lung Transplant 2019;38:1042-55.

2. Verleden GM, Glanville AR, Lease ED, et al. Chronic lung allograft dysfunction: Definition, diagnostic criteria, and approaches to treatment-A consensus report from the Pulmonary Council of the ISHLT. J Heart Lung Transplant 2019;38:493-503.

3. Sato M. Chronic lung allograft dysfunction after lung transplantation: the moving target. Gen Thorac Cardiovasc Surg 2013;61:67-78.

4. Royer PJ, Olivera-Botello G, Koutsokera A, et al. Chronic Lung Allograft Dysfunction: A Systematic Review of Mechanisms. Transplantation 2016;100:1803-14.

5. Dieudé M, West LJ, Muruve DA, et al. New Answers to Old Conundrums: What Antibodies, Exosomes and Inflammasomes Bring to the Conversation. Canadian National Transplant Research Program International Summit Report. Transplantation 2018;102:209-14.

6. Sato M, Waddell TK, Wagnetz U, et al. Restrictive allograft syndrome (RAS): a novel form of chronic lung allograft dysfunction. J Heart Lung Transplant 2011;30:735-42.

7. Gay NJ, Symmons MF, Gangloff M, et al. Assembly and localization of Toll-like receptor signalling complexes. Nat Rev Immunol 2014;14:546-58.

8. Satoh T, Akira S. Toll-Like Receptor Signaling and Its Inducible Proteins. Microbiol Spectr 2016. doi: 10.1128/ microbiolspec.MCHD-0040-2016.

9. Alegre ML, Leemans J, Le Moine A, et al. The multiple facets of toll-like receptors in transplantation biology. Transplantation 2008;86:1-9.

10. Schreibelt G, Tel J, Sliepen KH, et al. Toll-like receptor expression and function in human dendritic cell subsets: implications for dendritic cell-based anticancer immunotherapy. Cancer Immunol Immunother 2010;59:1573-82.

11. Akira $S$, Uematsu S, Takeuchi O. Pathogen recognition and innate immunity. Cell 2006;124:783-801.

12. Gazzinelli RT, Denkers EY. Protozoan encounters with Toll-like receptor signalling pathways: implications for host parasitism. Nat Rev Immunol 2006;6:895-906.

13. Kawai T, Akira S. Toll-like receptors and their crosstalk with other innate receptors in infection and immunity. Immunity 2011;34:637-50.

14. Leemans JC, Kors L, Anders HJ, et al. Pattern recognition receptors and the inflammasome in kidney disease. Nat Rev Nephrol 2014;10:398-414.

15. Land WG. Emerging role of innate immunity in organ transplantation part II: potential of damage-associated molecular patterns to generate immunostimulatory dendritic cells. Transplant Rev (Orlando) 2012;26:73-87.

16. Creagh-Brown BC, Quinlan GJ, Evans TW, et al. The RAGE axis in systemic inflammation, acute lung injury and myocardial dysfunction: an important therapeutic target? Intensive Care Medicine 2010;36:1644-56.

17. D'Agati V, Schmidt AM. RAGE and the pathogenesis of chronic kidney disease. Nature Reviews Nephrology 2010;6:352-60.

18. Christie JD, Shah CV, Kawut SM, et al. Plasma levels of receptor for advanced glycation end products, blood transfusion, and risk of primary graft dysfunction. Am J Respir Crit Care Med 2009;180:1010-5.

19. Sorci G, Riuzzi F, Giambanco I, et al. RAGE in tissue homeostasis, repair and regeneration. Biochim Biophys Acta 2013;1833:101-9.

20. He M, Kubo H, Ishizawa K, et al. The role of the receptor for advanced glycation end-products in lung fibrosis. Am J Physiol Lung Cell Mol Physiol 2007;293:L1427-36.

21. Ferhani N, Letuve S, Kozhich A, et al. Expression of high-mobility group box 1 and of receptor for advanced glycation end products in chronic obstructive pulmonary disease. Am J Respir Crit Care Med 2010;181:917-27.

22. Wu X, Mi Y, Yang H, et al. The activation of HMGB1 as a progression factor on inflammation response in normal human bronchial epithelial cells through RAGE/JNK/NFkappaB pathway. Mol Cell Biochem 2013;380:249-57.

23. Bierhaus A, Humpert PM, Morcos M, et al. Understanding RAGE, the receptor for advanced glycation end products. J Mol Med (Berl) 2005;83:876-86.

24. Uchida T, Shirasawa M, Ware LB, et al. Receptor for advanced glycation end-products is a marker of type I cell injury in acute lung injury. Am J Respir Crit Care Med 2006;173:1008-15.

25. Calfee CS, Budev MM, Matthay MA, et al. Plasma receptor for advanced glycation end-products predicts duration of ICU stay and mechanical ventilation in patients after lung transplantation. J Heart Lung Transplant 2007;26:675-80.

26. Arbore G, Kemper C. A novel "complement-metabolisminflammasome axis" as a key regulator of immune cell effector function. Eur J Immunol 2016;46:1563-73.

27. Weigt SS, Palchevskiy V, Belperio JA. Inflammasomes and IL-1 biology in the pathogenesis of allograft dysfunction. J 
Clin Invest 2017;127:2022-9.

28. Swanson KV, Deng M, Ting JPY. The NLRP3 inflammasome: molecular activation and regulation to therapeutics. Nature Reviews Immunology 2019;19:477-89.

29. Land WG, Agostinis P, Gasser S, et al. Transplantation and Damage-Associated Molecular Patterns (DAMPs). Am J Transplant 2016;16:3338-61.

30. Linkermann A, Stockwell BR, Krautwald S, et al. Regulated cell death and inflammation: an autoamplification loop causes organ failure. Nat Rev Immunol 2014;14:759-67.

31. Campisi L, Cummings RJ, Blander JM. Death-defining immune responses after apoptosis. Am J Transplant 2014;14:1488-98.

32. Doran AC, Yurdagul A Jr, Tabas I. Efferocytosis in health and disease. Nat Rev Immunol 2019. doi: 10.1038/s41577019-0240-6. [Epub ahead of print].

33. Martin M, Blom AM. Complement in removal of the dead - balancing inflammation. Immunol Rev 2016;274:218-32.

34. Favaloro B, Allocati N, Graziano V, et al. Role of apoptosis in disease. Aging (Albany NY) 2012;4:330-49.

35. Haque MA, Mizobuchi T, Yasufuku K, et al. Evidence for immune responses to a self-antigen in lung transplantation: role of type $\mathrm{V}$ collagen-specific $\mathrm{T}$ cells in the pathogenesis of lung allograft rejection. J Immunol 2002;169:1542-9.

36. Burlingham WJ, Love RB, Jankowska-Gan E, et al. IL17-dependent cellular immunity to collagen type $\mathrm{V}$ predisposes to obliterative bronchiolitis in human lung transplants. J Clin Invest 2007;117:3498-506.

37. Palmer SM, Burch LH, Davis RD, et al. The role of innate immunity in acute allograft rejection after lung transplantation. Am J Respir Crit Care Med 2003;168:628-32.

38. Palmer SM, Burch LH, Trindade AJ, et al. Innate immunity influences long-term outcomes after human lung transplant. Am J Respir Crit Care Med 2005;171:780-5.

39. Palmer SM, Klimecki W, Yu L, et al. Genetic regulation of rejection and survival following human lung transplantation by the innate immune receptor CD14. Am J Transplant 2007;7:693-9.

40. Kastelijn EA, van Moorsel CH, Rijkers GT, et al. Polymorphisms in innate immunity genes associated with development of bronchiolitis obliterans after lung transplantation. J Heart Lung Transplant 2010;29:665-71.

41. Kastelijn EA, van Moorsel CH, Ruven HJ, et al. Genetic polymorphisms and bronchiolitis obliterans syndrome after lung transplantation: promising results and recommendations for the future. Transplantation 2012;93:127-35.

42. Tesar BM, Jiang D, Liang J, et al. The role of hyaluronan degradation products as innate alloimmune agonists. Am J Transplant 2006;6:2622-35.

43. Todd JL, Wang X, Sugimoto S, et al. Hyaluronan contributes to bronchiolitis obliterans syndrome and stimulates lung allograft rejection through activation of innate immunity. Am J Respir Crit Care Med 2014;189:556-66.

44. Saito T, Liu M, Binnie M, et al. Distinct expression patterns of alveolar "alarmins" in subtypes of chronic lung allograft dysfunction. Am J Transplant 2014;14:1425-32.

45. Shah RJ, Bellamy SL, Lee JC, et al. Early plasma soluble receptor for advanced glycation end-product levels are associated with bronchiolitis obliterans syndrome. Am J Transplant 2013;13:754-9.

46. Zweers N, Petersen AH, van der Hoeven JA, et al. Donor brain death aggravates chronic rejection after lung transplantation in rats. Transplantation 2004;78:1251-8.

47. Avlonitis VS, Wigfield CH, Golledge HD, et al. Early hemodynamic injury during donor brain death determines the severity of primary graft dysfunction after lung transplantation. Am J Transplant 2007;7:83-90.

48. Sammani S, Park KS, Zaidi SR, et al. A sphingosine 1-phosphate 1 receptor agonist modulates brain deathinduced neurogenic pulmonary injury. Am J Respir Cell Mol Biol 2011;45:1022-7.

49. Wauters S, Somers J, De Vleeschauwer S, et al. Evaluating lung injury at increasing time intervals in a murine brain death model. J Surg Res 2013;183:419-26.

50. Rostron AJ, Cork DM, Avlonitis VS, et al. Contribution of Toll-like receptor activation to lung damage after donor brain death. Transplantation 2010;90:732-9.

51. Wang X, O'Brien ME, Yu J, et al. Prolonged Cold Ischemia Induces Necroptotic Cell Death in IschemiaReperfusion Injury and Contributes to Primary Graft Dysfunction after Lung Transplantation. Am J Respir Cell Mol Biol 2019;61:244-56.

52. Danobeitia JS, Sperger JM, Hanson MS, et al. Early activation of the inflammatory response in the liver of brain-dead non-human primates. J Surg Res 2012;176:639-48.

53. Shimamoto A, Pohlman TH, Shomura S, et al. Toll-like receptor 4 mediates lung ischemia-reperfusion injury. Ann Thorac Surg 2006;82:2017-23.

54. Ishiyama $T$, Dharmarajan $S$, Hayama $M$, et al. Inhibition of nuclear factor kappaB by IkappaB superrepressor gene 
transfer ameliorates ischemia-reperfusion injury after experimental lung transplantation. J Thorac Cardiovasc Surg 2005;130:194-201.

55. Zanotti G, Casiraghi M, Abano JB, et al. Novel critical role of Toll-like receptor 4 in lung ischemia-reperfusion injury and edema. Am J Physiol Lung Cell Mol Physiol 2009;297:L52-63.

56. Merry HE, Phelan P, Doak MR, et al. Role of toll-like receptor-4 in lung ischemia-reperfusion injury. Ann Thorac Surg 2015;99:1193-9.

57. Takahashi M, Chen-Yoshikawa TF, Menju T, et al. Inhibition of Toll-like receptor 4 signaling ameliorates lung ischemia-reperfusion injury in acute hyperglycemic conditions. J Heart Lung Transplant 2016;35:815-22.

58. Del Sorbo L, Costamagna A, Muraca G, et al. Intratracheal Administration of Small Interfering RNA Targeting Fas Reduces Lung Ischemia-Reperfusion Injury. Crit Care Med 2016;44:e604-13.

59. Xu HC, Lv W, Wang LM, et al. Early Protection by Resveratrol in Rat Lung Transplantation. Med Sci Monit 2019;25:760-70.

60. Kim H, Zamel R, Bai XH, et al. Ischemia-reperfusion induces death receptor-independent necroptosis via calpain-STAT3 activation in a lung transplant setting. Am J Physiol Lung Cell Mol Physiol 2018;315:L595-608.

61. Kanou T, Ohsumi A, Kim H, et al. Inhibition of regulated necrosis attenuates receptor-interacting protein kinase 1-mediated ischemia-reperfusion injury after lung transplantation. J Heart Lung Transplant 2018;37:1261-70.

62. Noda K, Tane S, Haam SJ, et al. Targeting Circulating Leukocytes and Pyroptosis During Ex Vivo Lung Perfusion Improves Lung Preservation. Transplantation 2017;101:2841-9.

63. Mallavia B, Liu F, Lefrancais E, et al. Mitochondrial DNA Stimulates TLR9-Dependent NET Formation in Primary Graft Dysfunction. Am J Respir Cell Mol Biol 2020;62:364-72.

64. Scozzi D, Ibrahim M, Liao F, et al. Mitochondrial damageassociated molecular patterns released by lung transplants are associated with primary graft dysfunction. Am J Transplant 2019;19:1464-77.

65. Sternberg DI, Gowda R, Mehra D, et al. Blockade of receptor for advanced glycation end product attenuates pulmonary reperfusion injury in mice. J Thorac Cardiovasc Surg 2008;136:1576-85.

66. He L, Sun F, Wang Y, et al. HMGB1 exacerbates bronchiolitis obliterans syndrome via RAGE/NF-kappaB/
HPSE signaling to enhance latent TGF-beta release from ECM. Am J Transl Res 2016;8:1971-84.

67. Sharma AK, LaPar DJ, Stone ML, et al. Receptor for advanced glycation end products (RAGE) on iNKT cells mediates lung ischemia-reperfusion injury. Am J Transplant 2013;13:2255-67.

68. Andrade CF, Kaneda H, Der S, et al. Toll-like receptor and cytokine gene expression in the early phase of human lung transplantation. J Heart Lung Transplant 2006;25:131723.

69. Cantu E, Lederer DJ, Meyer K, et al. Gene set enrichment analysis identifies key innate immune pathways in primary graft dysfunction after lung transplantation. Am J Transplant 2013;13:1898-904.

70. Cantu E, Suzuki Y, Diamond JM, et al. Protein Quantitative Trait Loci Analysis Identifies Genetic Variation in the Innate Immune Regulator TOLLIP in Post-Lung Transplant Primary Graft Dysfunction Risk. Am J Transplant 2016;16:833-40.

71. Xu Z, Sharma M, Gelman A, et al. Significant role for microRNA-2 1 affecting toll-like receptor pathway in primary graft dysfunction after human lung transplantation. J Heart Lung Transplant 2017;36:331-9.

72. Shafaghi S, Mortaz E, Abbasi Dezfuli A, et al. Normothermic Ex Vivo Lung Perfusion in Brain-dead Donors Reduces Inflammatory Cytokines and Toll-like Receptor Expression. Iran J Allergy Asthma Immunol 2016;15:340-54.

73. Pelaez A, Force SD, Gal AA, et al. Receptor for advanced glycation end products in donor lungs is associated with primary graft dysfunction after lung transplantation. Am J Transplant 2010;10:900-7.

74. Fiser SM, Tribble CG, Long SM, et al. Ischemiareperfusion injury after lung transplantation increases risk of late bronchiolitis obliterans syndrome. Ann Thorac Surg 2002;73:1041-7; discussion 1047-8.

75. Keshavjee S, Davis RD, Zamora MR, et al. A randomized, placebo-controlled trial of complement inhibition in ischemia-reperfusion injury after lung transplantation in human beings. J Thorac Cardiovasc Surg 2005;129:423-8.

76. Thabut G, Mal H, Cerrina J, et al. Graft ischemic time and outcome of lung transplantation: a multicenter analysis. Am J Respir Crit Care Med 2005;171:786-91.

77. Daud SA, Yusen RD, Meyers BF, et al. Impact of immediate primary lung allograft dysfunction on bronchiolitis obliterans syndrome. Am J Respir Crit Care Med 2007;175:507-13.

78. Whitson BA, Prekker ME, Herrington CS, et al. Primary 
graft dysfunction and long-term pulmonary function after lung transplantation. J Heart Lung Transplant 2007;26:1004-11.

79. Huang HJ, Yusen RD, Meyers BF, et al. Late primary graft dysfunction after lung transplantation and bronchiolitis obliterans syndrome. Am J Transplant 2008;8:2454-62.

80. DerHovanessian A, Weigt SS, Palchevskiy V, et al. The Role of TGF-beta in the Association Between Primary Graft Dysfunction and Bronchiolitis Obliterans Syndrome. Am J Transplant 2016;16:640-9.

81. Mauck KA, Hosenpud JD. The bronchial epithelium: a potential allogeneic target for chronic rejection after lung transplantation. J Heart Lung Transplant 1996;15:709-14.

82. Waddell TK, Gorczynski RM, DeCampos KN, et al. Major histocompatibility complex expression and lung ischemia-reperfusion in rats. Ann Thorac Surg 1996;62:866-72.

83. Bharat A, Narayanan K, Street T, et al. Early posttransplant inflammation promotes the development of alloimmunity and chronic human lung allograft rejection. Transplantation 2007;83:150-8.

84. Bharat A, Kuo E, Steward N, et al. Immunological link between primary graft dysfunction and chronic lung allograft rejection. Ann Thorac Surg 2008;86:189-95; discussion 196-7.

85. Watanabe T, Martinu T, Chruscinski A, et al. A B celldependent pathway drives chronic lung allograft rejection after ischemia-reperfusion injury in mice. Am J Transplant 2019;19:3377-89.

86. Dickson RP, Erb-Downward JR, Freeman CM, et al. Changes in the lung microbiome following lung transplantation include the emergence of two distinct Pseudomonas species with distinct clinical associations. PLoS One 2014;9:e97214.

87. Chong AS, Alegre ML. The impact of infection and tissue damage in solid-organ transplantation. Nat Rev Immunol 2012;12:459-71.

88. Botha P, Archer L, Anderson RL, et al. Pseudomonas aeruginosa colonization of the allograft after lung transplantation and the risk of bronchiolitis obliterans syndrome. Transplantation 2008;85:771-4.

89. Gottlieb J, Mattner F, Weissbrodt H, et al. Impact of graft colonization with gram-negative bacteria after lung transplantation on the development of bronchiolitis obliterans syndrome in recipients with cystic fibrosis. Respir Med 2009;103:743-9.

90. Yamamoto S, Nava RG, Zhu J, et al. Cutting edge: Pseudomonas aeruginosa abolishes established lung transplant tolerance by stimulating B7 expression on neutrophils. J Immunol 2012;189:4221-5.

91. Gregson AL, Wang X, Weigt SS, et al. Interaction between Pseudomonas and CXC chemokines increases risk of bronchiolitis obliterans syndrome and death in lung transplantation. Am J Respir Crit Care Med 2013;187:518-26.

92. Vital D, Hofer M, Benden C, et al. Impact of sinus surgery on pseudomonal airway colonization, bronchiolitis obliterans syndrome and survival in cystic fibrosis lung transplant recipients. Respiration 2013;86:25-31.

93. Kumar D, Erdman D, Keshavjee S, et al. Clinical impact of community-acquired respiratory viruses on bronchiolitis obliterans after lung transplant. Am J Transplant 2005;5:2031-6.

94. Allyn PR, Duffy EL, Humphries RM, et al. Graft Loss and CLAD-Onset Is Hastened by Viral Pneumonia After Lung Transplantation. Transplantation 2016;100:2424-31.

95. Thomas LD, Milstone AP, Miller GG, et al. Longterm outcomes of cytomegalovirus infection and disease after lung or heart-lung transplantation with a delayed ganciclovir regimen. Clin Transplant 2009;23:476-83.

96. Paraskeva M, Bailey M, Levvey BJ, et al. Cytomegalovirus replication within the lung allograft is associated with bronchiolitis obliterans syndrome. Am J Transplant 2011;11:2190-6.

97. Calabrese DR, Chong T, Wang A, et al. NKG2C Natural Killer Cells in Bronchoalveolar Lavage Are Associated With Cytomegalovirus Viremia and Poor Outcomes in Lung Allograft Recipients. Transplantation 2019;103:493-501.

98. Weigt SS, Elashoff RM, Huang C, et al. Aspergillus colonization of the lung allograft is a risk factor for bronchiolitis obliterans syndrome. Am J Transplant 2009;9:1903-11.

99. Weigt SS, Copeland CAF, Derhovanessian A, et al. Colonization with small conidia Aspergillus species is associated with bronchiolitis obliterans syndrome: a twocenter validation study. Am J Transplant 2013;13:919-27.

100. Shino MY, DerHovanessian A, Sayah DM, et al. The Impact of Allograft CXCL9 during Respiratory Infection on the Risk of Chronic Lung Allograft Dysfunction. OBM Transplant 2018. doi: 10.21926/obm.transplant.1804029.

101. Tikkanen JM, Kallio EA, Bruggeman CA, et al. Prevention of cytomegalovirus infection-enhanced experimental obliterative bronchiolitis by antiviral prophylaxis or immunosuppression in rat tracheal allografts. Am J Respir Crit Care Med 2001;164:672-9. 
102. Tikkanen JM, Krebs R, Bruggeman C, et al. Plateletderived growth factor regulates cytomegalovirus infectionenhanced obliterative bronchiolitis in rat tracheal allografts. Transplantation 2004;77:655-8.

103. Wiebe K, Fraund S, Steinmuller C, et al. Rat cytomegalovirus and Listeria monocytogenes infection enhance chronic rejection after allogenic rat lung transplantation. Transpl Int 2005;18:1166-74.

104.Kuo E, Bharat A, Goers T, et al. Respiratory viral infection in obliterative airway disease after orthotopic tracheal transplantation. Ann Thorac Surg 2006;82:1043-50.

105. Suzuki S, Sugawara T, Tabata T, et al. Sivelestat reduces reperfusion injury of lungs harvested from endotoxinprimed rats by inhibition of neutrophil-mediated inflammation. J Heart Lung Transplant 2007;26:370-5.

106. Martinu T, Kinnier CV, Gowdy KM, et al. Innate immune activation potentiates alloimmune lung disease independent of chemokine (C-X-C motif) receptor 3. J Heart Lung Transplant 2011;30:717-25.

107. Atanasova S, Hirschburger M, Jonigk D, et al. A relevant experimental model for human bronchiolitis obliterans syndrome. J Heart Lung Transplant 2013;32:1131-9.

108. Evers A, Atanasova S, Fuchs-Moll G, et al. Adaptive and innate immune responses in a rat orthotopic lung transplant model of chronic lung allograft dysfunction. Transpl Int 2015;28:95-107.

109.Law N, Hamandi B, Fegbeutel C, et al. Lack of association of Aspergillus colonization with the development of bronchiolitis obliterans syndrome in lung transplant recipients: An international cohort study. J Heart Lung Transplant 2019;38:963-71.

110.Pritchard J, Thakrar MV, Somayaji R, et al. Epidemic Pseudomonas aeruginosa infection in patients with cystic fibrosis is not a risk factor for poor clinical Outcomes following lung transplantation. J Cyst Fibros 2016;15:392-9.

111. Schott C, Weigt SS, Turturice BA, et al. Bronchiolitis obliterans syndrome susceptibility and the pulmonary microbiome. J Heart Lung Transplant 2018;37:1131-40.

112. Willner DL, Hugenholtz P, Yerkovich ST, et al. Reestablishment of recipient-associated microbiota in the lung allograft is linked to reduced risk of bronchiolitis obliterans syndrome. Am J Respir Crit Care Med 2013;187:640-7.

113.Davis RD Jr, Lau CL, Eubanks S, et al. Improved lung allograft function after fundoplication in patients with gastroesophageal reflux disease undergoing lung transplantation. J Thorac Cardiovasc Surg
2003;125:533-42.

114. Bobadilla JL, Jankowska-Gan E, Xu Q, et al. Refluxinduced collagen type $\mathrm{V}$ sensitization: potential mediator of bronchiolitis obliterans syndrome. Chest 2010;138:363-70.

115. Hartwig MG, Anderson DJ, Onaitis MW, et al. Fundoplication after lung transplantation prevents the allograft dysfunction associated with reflux. Ann Thorac Surg 2011;92:462-8; discussion; 468-9.

116.Hartwig MG, Appel JZ, Li B, et al. Chronic aspiration of gastric fluid accelerates pulmonary allograft dysfunction in a rat model of lung transplantation. J Thorac Cardiovasc Surg 2006;131:209-17.

117. Meltzer AJ, Weiss MJ, Veillette GR, et al. Repetitive gastric aspiration leads to augmented indirect allorecognition after lung transplantation in miniature swine. Transplantation 2008;86:1824-9.

118. Tang T, Chang JC, Xie A, et al. Aspiration of gastric fluid in pulmonary allografts: effect of $\mathrm{pH}$. J Surg Res 2013;181:e31-8.

119.D'Ovidio F, Mura M, Ridsdale R, et al. The effect of reflux and bile acid aspiration on the lung allograft and its surfactant and innate immunity molecules SP-A and SP-D. Am J Transplant 2006;6:1930-8.

120. Blondeau K, Mertens V, Vanaudenaerde BA, et al. Nocturnal weakly acidic reflux promotes aspiration of bile acids in lung transplant recipients. J Heart Lung Transplant 2009;28:141-8.

121. King BJ, Iyer H, Leidi AA, et al. Gastroesophageal reflux in bronchiolitis obliterans syndrome: a new perspective. J Heart Lung Transplant 2009;28:870-5.

122.D'Ovidio F, Mura M, Tsang M, et al. Bile acid aspiration and the development of bronchiolitis obliterans after lung transplantation. J Thorac Cardiovasc Surg 2005;129:1144-52.

123. Blondeau K, Mertens V, Vanaudenaerde BA, et al. Gastrooesophageal reflux and gastric aspiration in lung transplant patients with or without chronic rejection. Eur Respir J 2008;31:707-13.

124. Mertens V, Blondeau K, Van Oudenhove L, et al. Bile acids aspiration reduces survival in lung transplant recipients with BOS despite azithromycin. Am J Transplant 2011;11:329-35.

125.Nawrot TS, Vos R, Jacobs L, et al. The impact of traffic air pollution on bronchiolitis obliterans syndrome and mortality after lung transplantation. Thorax 2011;66:748-54.

126. Bhinder S, Chen H, Sato M, et al. Air pollution and the development of posttransplant chronic lung allograft 
dysfunction. Am J Transplant 2014;14:2749-57.

127. Verleden SE, Scheers H, Nawrot TS, et al. Lymphocytic bronchiolitis after lung transplantation is associated with daily changes in air pollution. Am J Transplant 2012;12:1831-8.

128. Ruttens D, Verleden SE, Bijnens EM, et al. An association of particulate air pollution and traffic exposure with mortality after lung transplantation in Europe. Eur Respir J 2017. doi: 10.1183/13993003.00484-2016.

129. Benmerad M, Slama R, Botturi K, et al. Chronic effects of air pollution on lung function after lung transplantation in the Systems prediction of Chronic Lung Allograft Dysfunction (SysCLAD) study. Eur Respir J 2017. doi: 10.1183/13993003.00206-2016.

130. Tomasek JJ, Gabbiani G, Hinz B, et al. Myofibroblasts and mechano-regulation of connective tissue remodelling. Nat Rev Mol Cell Biol 2002;3:349-63.

131. Oberbarnscheidt MH, Zeng Q, Li Q, et al. Non-self recognition by monocytes initiates allograft rejection. J Clin Invest 2014;124:3579-89.

132.Dai H, Friday AJ, Abou-Daya KI, et al. Donor SIRPalpha polymorphism modulates the innate immune response to allogeneic grafts. Sci Immunol 2017. doi: 10.1126/ sciimmunol.aam6202.

133. de Perrot M, Young K, Imai Y, et al. Recipient T cells mediate reperfusion injury after lung transplantation in the rat. J Immunol 2003;171:4995-5002.

134.Yang Z, Sharma AK, Linden J, et al. CD4+ T lymphocytes mediate acute pulmonary ischemiareperfusion injury. J Thorac Cardiovasc Surg 2009;137:695-702; discussion 702.

135. Moshkelgosha S, Levy L, Martinu T, et al. Longitudinal Mass Cytometric Profiling of BAL Cells in Lung Transplant Recipients. J Heart Lung Transplant 2018;37:S216.

136. Moshkelgosha S, Levy L, Martinu T, et al. Emergence of a Specific Intrapulmonary CD4+ T Cell Subset Prior to the Onset of Lung Allograft Dysfunction. J Heart Lung Transplant 2019;38:S17.

137. Borthwick LA, Suwara MI, Carnell SC, et al. Pseudomonas aeruginosa Induced Airway Epithelial Injury Drives Fibroblast Activation: A Mechanism in Chronic Lung Allograft Dysfunction. Am J Transplant 2016;16:1751-65.

138. Seki E, De Minicis S, Osterreicher CH, et al. TLR4 enhances TGF-beta signaling and hepatic fibrosis. Nat Med 2007;13:1324-32.

139. Kawashima M, Sato M, Murakawa T, et al. Role of Tolllike Receptor 4 Expressed by Fibroblasts in Allograft Fibrosis in Mouse Orthotopic Tracheal Transplantation. Transplant Proc 2018;50:3863-72.

140. Vandermeulen E, Lammertyn E, Verleden SE, et al. Immunological diversity in phenotypes of chronic lung allograft dysfunction: a comprehensive immunohistochemical analysis. Transpl Int 2017;30:134-43.

141. Sato M, Hwang DM, Ohmori-Matsuda K, et al. Revisiting the pathologic finding of diffuse alveolar damage after lung transplantation. J Heart Lung Transplant 2012;31:354-63.

142.Levy L, Tigert A, Huszti E, et al. Epithelial cell death markers in bronchoalveolar lavage correlate with chronic lung allograft dysfunction subtypes and survival in lung transplant recipients-a single-center retrospective cohort study. Transpl Int 2019;32:965-73.

143. Watanabe T, Boonstra K, Horie M, et al. Repeated Episodes of Airway Inflammation Augment Acute Rejection and Fibrosis in a Mouse Lung Transplant Model. J Heart Lung Transplant 2018;37:S81-2.

144. Takahagi A, Sato M, Chen-Yoshikawa TF, et al. LPSinduced airway-centered inflammation leading to BOS-like airway remodeling distinct from RAS-like fibrosis in rat lung transplantation. Transplantation 2020. [Epub ahead of print].
Cite this article as: Kawashima $\mathrm{M}$, Juvet SC. The role of innate immunity in the long-term outcome of lung transplantation. Ann Transl Med 2020;8(6):412. doi: 10.21037/ atm.2020.03.20 